\title{
Systematic Review on How the Delivery of Vision Care Policies Affects Students' Academic Performance and Mental Health
}

\author{
Jason Hung $^{1}$ \\ ${ }^{1}$ Institute of Education, University College London, London, the United Kingdom \\ Correspondence: Jason Hung. E-mail: sociowriting@jasehung.com
}

Received: February 20, 2020

Accepted: June 22, 2020

Online Published: June 29, 2020

doi:10.5539/ass.v16n7p94

URL: https://doi.org/10.5539/ass.v16n7p94

\begin{abstract}
This is a systematic review that examines how the delivery of vision care policies, namely (1) vision acuity (VA) testing, (2) subsidized or free spectacles, (3) spectacle prescriptions, (4) vision care education and (5) time spent outdoors and/or away from a variety of near-work activities affect students' academic performance and mental health. Relevant literature in both Chinese and non-Chinese contexts is studied. However, existing literature (1) focusing on post-secondary school students and adults, (2) presenting qualitative research, and (3) adopting non-experimental designs is excluded.
\end{abstract}

Keywords: vision care, academic performance, mental health, intervention policies

\section{Description of the Intervention}

As per the framework of this systematic review, existing literature (1) focusing on post-secondary school students and adults, (2) presenting qualitative research, and (3) adopting non-experimental designs is excluded. Relevant studies describe and analyze a range of vision care interventions, including vision acuity (VA) testing, subsidized or free spectacles, spectacle prescriptions, vision care education, and time spent outdoors and/or away from a variety of near-work activities.

VA testing. A total of 5,736 rural preschool children were assigned to three VA screening groups in a randomized trial carried out in Northwest China in 2015. These groups were screened by (1) teachers, (2) local optometrists and (3) volunteers. Accuracy through screening was compared with screenings executed by experienced optometrists. Results indicated the accuracy of screening by teachers, local optometrists and volunteers was equivalent, though the use of teachers was most cost-effective (Wang, Congdon, Hogg, Zhang, Li, Shi, Jin, He, Wang, Boswell \& Iyer, 2019).

Yue Ma., Nathan Congdon, Yaojiang, Shi, Ruth Hogg, Alexis Medina, Matthew Boswell, Scott Rozelle and Mony Iyer (2018), in part, studied the effect of hospital-based vision centers on spectacle ownership and spectacle-wearing behaviors among rural primary students in Yongshou County, Shaanxi Province, China, between September 2014 through June 2015. Rural students from grades four through six from all 31 rural primary schools countywide participated in a randomized trial. A total of 543 and 657 participants were randomized to early VA screening and late VA screening groups, led by their teachers. Results demonstrated that $80 \%$ and $75 \%$ of those from the early vision screening groups owned and wore eyeglasses respectively, compared to $61 \%$ and $55 \%$ of their counterparts in the late screening groups. Here findings revealed early VA screening could encourage positive vision care behaviors among rural students.

Beyond Chinese contexts, the rates of VA testing in India, especially in urban areas, have been growing. Among 205,082 students who failed screening in a nationwide vision screening program, 43,922 were given spectacles and 42,390 (96.5\%) were wearing their spectacles in class. In sub-Saharan Africa, however, human and financial resources available for vision screening programs are very limited. In addition, little information on the prevalence of uncorrected refractive errors has been available regionwide. Alternatively, VA testing programs for school-aged children are readily available in the United States (Powell, Evans and Morjaria, 2004). Eileen Mayro, Lisa Hark, Eric Shiuey, Michael Pond, Linda Siam, Marlee Silverstein, Ann Murchison and Alex Levin (2018) assessed the Wills Eye Vision Screening Program for Children, a community-based pediatric vision screening program, adopted in public schools in Philadelphia. They argued myopia created learning challenges at class, while school-based vision screening programs successfully provided an avenue to identify and correct 
students' refractive errors. A VA testing cum intervention program, for example, spectacle delivery, with periodic evaluation is also applicable in Nepal as $97 \%$ of school-aged children's eye diseases are preventable or treatable, including the development of myopia (Nepal, Koirala, Adhikary, and Sharma, 2003).

Provision of free spectacles and prescription of spectacles. Xiaochen Ma, Zhong Zhou, Hongmei Yi, Xiaopeng Pang, Yaojiang Shi, Qianyun Chen, Mirjam Meltzer, Saskia Cessie, Mingguang He, Scott Rozelle, Yizhi Liu and Nathan Congdon (2014) measured the effects of the provision of free spectacles on rural Chinese students' vision ability. A sum of 3,052 rural primary students, in the fourth and fifth grade, in two prefectures in western China were randomly sampled. Children were randomized by schools to one of the three groups: (1) prescription of glasses only - the control group; (2) provision of vouchers for students to acquire free glasses at a local facility the intervention group; or (3) provision of free glass in class - a further intervention group. Findings demonstrated $41 \%$ of students from the intervention groups wore glasses, compared to $26 \%$ from the control group. These outcomes echoed findings of Hongyu Guan, Huan Wang, Juerong Huang, Kang Du, Jin Zhao, Matthew Boswell, Yaojiang Shi, Mony Iyer and Scott Rozelle (2018a)'s study, where spectacle uptake rates were higher among rural primary school students who were granted vouchers to acquire free glasses, than those who were only given prescriptions of glasses. Additionally, Paul Glewwe, Meng Zhao and Albert Park (2012) examined health-related intervention in the form of the provision of spectacles to fourth to sixth grade rural primary school students with poor vision in Yongdeng and Tianzhu counties in 2004. Students from nine townships each in Yongdeng county were assigned to the intervention group - benefiting from free eyeglasses and the control group - receiving no free eyeglasses. In Tianzhu county, students from ten townships were allocated to the intervention group and nine to the control group. They found that girls were more likely to refuse to wear eyeglasses. Households indicating insufficient parental awareness of child vision problems, lower maternal educational attainment and poorer economic wellbeing significantly inhibited child access to glasses, unless free glasses were distributed.

In a study conducted in urban Guangzhou, China, myopic junior high school students, aged between 12 and 15, were randomly assigned to receive ready-made spectacles (RMS) or custom spectacles (CS). While VA was better among students with CS, students did not demonstrate a difference in acceptability with the use of RMS or CS. The study suggested that the distribution of RMS rather than CS should be a more financially sustainable school-based intervention in urban China (Zang, Keay, He, Mai, Munoz, Brady and Friedman, 2009). Another randomized clinical trial recruited 23,345 Indian children aged between eleven and 15 in 2015. Results also indicated the distribution of RMS could effectively correct children's VA and substantially reduce financial costs, relative to the allocation of CS (Morjaria, Evans, Murali, and Gilbert, 2017).

Vision care education. To assess whether educational intervention can encourage the purchase of spectacles among myopic rural Chinese students, 10 classes were randomly selected from all junior and senior high schools in three rural townships of Fuyang, Xichang, Liangying and Chaoshan, by Nathan Congdon, Liping Li, Mingzhi Zhang, Amy Yang, Yang Gao, Sian Griffiths, Jia Jiasi, Abhishek Sharma and Dennis Lam (2011). A total of 2,236 rural students in intervention groups were recommended to purchase glasses, and received vision care education in the form of a lecture, in addition to video and classroom demonstration promoting spectacle purchase. Another 2,212 students in control groups were only recommended to buy spectacles. A sum of $25.7 \%$ (417 students) from intervention groups and 34.0\% from control groups purchased spectacles, indicating that vision care education alone failed to increase myopic students' willingness to purchase eyeglasses.

Outdoor Activities. Juxiang Jin, Wenjuan Hua, Xuan Jiang, Xiaoyan Wu, Jiwen Yang, Guopeng Gao, Yun Fang, Chenlu Pei, Song Wang, Jiezheng Zhang, Liming Tao and Fangbiao Tao (2015) explored the prevalence, correlates and consequences of poor vision among two primary schools (grade one to five, aged between six and eleven) and two junior high schools (grade seven and eight, aged between twelve and fourteen) in Sujiatun District, Shenyang, Northeast China. A total of 3,051 students took part in the study, randomly distributed into either the intervention or control group. Students from the intervention group, relative to those from the control group, were given two additional recess sessions daily, each of 20 minutes, encouraging their participation in outdoor activities within a period of one academic year. Students from both the intervention and control group were subject to VA testing. Findings supported an increase in outdoor activities helped prevent myopia onset and myopic shift among primary and junior high school students. An extra 9-month cluster randomized controlled trial indicated the adoption of a weekend outdoor program in Singapore significantly helped prevent myopia among school-aged children (Ngo, Pan, Finkelstein, Lee, Wong, Ong, Ang, Wong and Saw, 2014).

Moreover, Aida Giloyan, Tsovinar Harutyunyan and Varduhi Petrosyan (2016) examined the risk factors for myopia among school-aged children in urban and urban Armenia. They found that the amount of near-work activities, apart from intensive reading, failed to play a key role in students' development of myopia in both 
urban and rural contexts.

\section{How the Intervention Might Work}

Rural Chinese primary students between the third and fifth grade in Gansu were found to be somewhat more vulnerable to vision problems when they enjoyed higher socioeconomic status (SES) and were more academically engaged (Hannum \& Zhang 2012). Epidemiological evidence argued this was because students doing more homework and reading more were expected to have slightly poorer vision and improved academic performance (Yi, Zhang, Ma, Congdon, Shi, Pang, Zeng, Wang, Boswell, \& Rozelle, 2015). Alternatively, when students' vision continued to worsen, randomized trial findings, also conducted in Gansu, demonstrated these rural primary cohorts were subject to poorer test scores than their counterparts with normal vision (ibid).

Additional randomized trials of 19,185 and 3,177 students carried out in Gansu showed that vision correction through wearing spectacles had significantly favorable effects on math and literacy performance, and class promotion (Hannum and Zhang 2012; Ma, Zhou, Yi, Pang, Shi, Chen, Meltzer, Cessie, He, Rozelle, Liu, \& Congdon, 2014). Another randomized trial, again held in Gansu, found that students wearing spectacles, when needed, enjoyed the equivalent of between 0.33 and 0.50 years of schooling more than their myopic counterparts without glasses (Glewwe et al., 2012).

In the United States, a randomized trial was conducted in 12 underprivileged public schools in Baltimore City. Among 262 second and third graders, 182 myopic students were given spectacles while the remaining 80 students did not have vision problems. All participants undertook reading assessments (i.e. the Letter-Word identification and Word Attack scales from the Woodcock Language Proficiency Battery) in the fall and winter of 2014/15. Findings demonstrated students receiving glasses improved more on Woodcock reading assessments than those who never required the use of spectacles. The provision of eyeglasses for disadvantaged myopic American students could improve their reading performance (Slavin, Collins, Repka, Friedman, Mudie, Owoeye and Madden, 2018).

In a more recent study carried out in Mojiang, Southeast China, the impact of spectacle use on seventh grade rural Chinese students' health-related quality of life (HRQOL) was assessed. Students not using spectacles suffered from a lower HRQOL score compared to those using spectacles in terms of psychological health (65.91 vs. $70.59, \mathrm{P}=0.028)$, emotional health (56.85 vs. $63.24, \mathrm{P}=0.028)$ and social functioning $(72.99$ vs. $78.60, \mathrm{P}=$ 0.036 ). Here findings revealed that visually impaired students without spectacles experienced a significantly worse mental health than those with spectacles (Deng-Juan Qian 2018).

Hongmei Yi, Linxiu Zhang, Xiaochen Ma, Nathan Congdon, Yaojiang Shi, Xiaopeng Pang, Junxia Zeng, Lei Wang, Matthew Boswell and Scott Rozelle (2015) found that impaired vision, measured by Early Treatment Diabetic Retinopathy Study (ETDRS) eye charts, was positively and significantly associated with poorer mental health, including an increase in anxiety levels. The magnitude of the correlation between VA and mental health grew when students' vision deteriorated from mild poor vision to severe poor vision.

Hongyu Guan, Huan Wang, Kang Du, Jin Zhao, Matthew Boswell, Yaojiang Shi, Yiwei Qian (2018b) carried out a cluster-randomized trial across 252 rural primary schools in China to study the impact of eyeglasses provision on the mental health of myopic students in 2013. In contrast with other relevant studies, Guan et al. found that the provision of free spectacles, or wearing spectacles, did not improve the mental health of rural students. Interestingly, findings showed that students developed a higher degree of learning anxiety when they engaged in low study intensity, compared to those participating in higher study intensity. Unfortunately, Guan et al. failed to investigate whether students from the intervention group - with access to free glasses - or from the control group - with no free glasses - engaged in higher study intensity, a factor which might play a role in students' mental health.

\section{References}

Congdon, N., Li, L., Zhang, M., Yang, A., Gao, Y., Griffiths, S., Wu, J., Sharma, A., \& Lam, D. (2011). Randomized, Controlled Trial of an Educational Intervention to Promote Spectacle Use in Rural China: The See Well to Learn Well Study. The American Academy of Ophthalmology, 118(12), 2343-50. https://doi.org/10.1016/j.ophtha.2011.06.016

Gian, D., Zhong, H., Li, J., Liu, H., \& Pan, C. (2018). Spectacles Utilization and Its Impact on Health-Related Quality of Life Among Rural Chinese Adolescents. Eye, 32(12), 1879-85. https://doi.org/10.1038/s41433-018-0197-x

Giloyan, A., Harutyunyan, T., \& Petrosyan, V. (2016). Risk Factors for Developing Myopia among Schoolchildren in Yerevan and Gegharkunik Province, Armenia. Ophthalmic Epidemiology, 24(2), 97-103. 
https://doi.org/10.1080/09286586.2016.1257028

Glewwe, P., Meng, Z., \& Park, A. (2012). Visualizing Development: Eyeglasses and Academic Performance in Rural Primary Schools in China. Working Paper WP12-2. St. Paul, M.N.: Center for International Food and Agricultural Policy: University of Minnesota.

Guan, H., Wang, H., Du, K., Zhao, J., Boswell, M., Shi, Y., \& Qian, Y. (2018b). The Effect of Providing Free Eyeglasses on Children's Mental Health Outcomes in China: A Cluster-Randomized Controlled Trial. International Journal of Environmental Research and Public Health, 15(12), 2749. https://doi.org/10.3390/ijerph15122749

Guan, H., Wang, H., Huang, J., Du, K., Zhao, J., Boswell, M., Shi, Y., Iyer, M., \& Rozelle, S. (2018a). Health Seeking Behavior among Rural Left-Behind Children: Evidence from Shaanxi and Gansu Provinces in China. International Journal of Environmental Research and Public Health, 15(3), 883. https://doi.org/10.3390/ijerph15050883

Hannum, E., \& Zhang, Y. (2012). Poverty and Proximate Barriers to Learning: Vision Deficiencies, Vision Correction and Educational Outcomes in Rural Northwest China. World Development, 40(9), 1921-31. https://doi.org/10.1016/j.worlddev.2012.04.029

Jin, J., Huan, W., Jiang, X., Wu, X., Yang, J., Gao, G., Fang, Y., Pei, C., Wang, S., Zhang, J., Tao, L., \& Tao, F. (2015). Effect of Outdoor Activity on Myopia Onset and Progression in School-Aged Children in Northeast $\begin{array}{lllllll}\text { China: The Sujiatun Eye Care Study. BMC Ophthalmology, } & 15, & 73 .\end{array}$ https://doi.org/10.1186/s12886-015-0052-9

Ma, X., Zhou, Z., Yi, H., Pang, X., Shi, Y., Chen, Q., Meltzer, M., Cessie, S., He, M., Rozelle, S., Liu, Y., \& Congdon, N. (2014). Effect on Providing Free Glasses on Children's Educational Outcomes in China: Cluster Randomized Controlled Trial. BMJ, 349, 5749. https://doi.org/10.1136/bmj.g5740

Ma, Y., Congdon, N., Shi, Y., Hogg, R., Medina, A., Boswell, M., Rozelle, S., \& Iyer, M. (2018). Effect of a Local Vision Care Centre on Eyeglasses Use and School Performance in Rural China: A Cluster $\begin{array}{lllll}\text { Randomized Clinical Trial. JAMA Ophthalmology, } & \text { 136(7), }\end{array}$ https://doi.org/10.1001/jamaophthalmol.2018.1329

Mayro, E., Hark, L., Shiuey, E., Silverstein, M., Pond, M., Siam, L., Murchison, A., \& Levin, A. (2018). Prevalence of Uncorrected Refractive Errors among School-Aged Children in the School District of Philadelphia. Journal of American Association for Pediatric Ophthalmology and Strabismus, 22(3), 214-7. https://doi.org/10.1016/j.jaapos.2018.07.222

Morjaria, P., Evans, J., Murali, K., \& Gilbert, C. (2017). Spectacle Wear among Children in a School-Based Program for Ready-Made vs. Custom-Made Spectacles in India: A Randomized Clinical Trial. JAMA Ophthalmology, 135(6), 527-33. https://doi.org/10.1001/jamaophthalmol.2017.0641

Nepal, B., Koirala, S., Adhikary, S., \& Sharma, A. (2003). Ocular Morbidity in Schoolchildren in Kathmandu. British Journal of Ophthalmology, 87(5), 531-4. https://doi.org/10.1136/bjo.87.5.531.

Ngo, C., Pan, C., Finkelstein, E., Lee, C., Wong, I., Ong, J., Ang, M., Wong, T., \& Saw, S. (2014). A Cluster Randomized Controlled Trial Evaluating an Incentive-Based Outdoor Physical Activity Program to Increase Outdoor Time and Prevent Myopia in Children. Ophthalmic and Physiological Optics, 34(3), 362-8. https://doi.org/10.1111/opo.12112

Powell, C., Evans, J., \& Morjaria, P. (2004). Vision Screening for Correctable Visual Acuity Deficits in School-Aged Children and Adolescents (Review). Cochrane Systematic Review, 2(2). https://doi.org/10.1002/14651858.CD005023.pub3

Slavin, R., Collins, M., Repka, M., Friedman, D., Mudie, L., Owoeye, J., \& Madden, N. (2018). In Plain Sight: Reading Outcomes of Providing Eyeglasses to Disadvantaged Children. Journal of Education for Students Placed at Risk (JESPAR), 23(3), 250-8. https://doi.org/10.1080/10824669.2018.1477602

Wang, L., Congdon, N., Hogg, R., Zhang, S., Li, M., Shi, Y., Jin, L., He, F., Wang, H., Boswell, M., \& Iyer, M. (2019). The Cost-Effectiveness of Alternative Vision Screening Models Among Preschool Children in Rural China. Acta Ophthalmologica, 97(3), 419-25. https://doi.org/10.1111/aos.13954

Yi, H., Zhang, L., Ma., X., Congdon, N., Shi, Y., Pang, X., Zeng, J., Wang, L., Boswell, M., \& Rozelle S. (2015). Poor Vision Among China's Rural Primary School Students: Prevalence, Correlates and Consequences. China Economic Review, 33(C), 247-62. https://doi.org/10.1016/j.chieco.2015.01.004 
Zang, Y., Keay, L., He., M., Mai, J., Munoz, B., Brady, C., \& Friedman, D. (2009). A Randomized, Clinical Trial Evaluating Ready-Made and Custom Spectacles Delivered via a School-Based Screening Program in China. Ophthalmology, 116(10), 1839-1845. https://doi.org/10.1016/j.ophtha.2009.04.004

\section{Copyrights}

Copyright for this article is retained by the author(s), with first publication rights granted to the journal.

This is an open-access article distributed under the terms and conditions of the Creative Commons Attribution license (http://creativecommons.org/licenses/by/4.0/). 